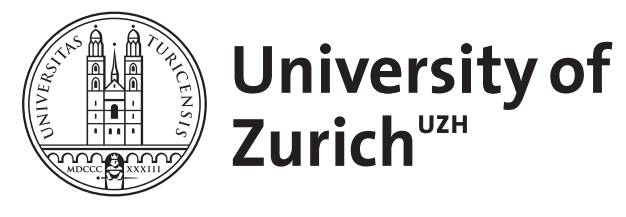

\title{
WNT4 and sex development
}

\author{
Biason-Lauber, A ; Konrad, D
}

\begin{abstract}
Although factors involved in male sexual differentiation have been well studied, the pathways regulating female sexual differentiation remain incompletely defined. To date, no genes have been identified to play a similar role in ovarian development as was shown for the SRY or SOX9 genes in testicular development. In mice, Wnt4 regulates the development of the female reproductive tract, antagonizes the production of testosterone, and is important for oocyte development. The recent demonstration of heterozygous WNT4 defects in patients with Mullerian agenesis and signs of ovarian hyperandrogenism added WNT4 to the growing list of genes such as SRY, SOX9, WT1, DAX1, and SF-1 contributing to human sexual development. In particular, WNT4 was the first human gene to be identified to direct development of the bipotential gonad towards ovaries. From a more clinical point of view, it seems that the absence of a uterus (and not other Müllerian abnormalities) and the androgen excess are the pathognomonic signs of WNT4 defects, suggesting that WNT4 deficiency might be a clinical entity distinct from the typical Mayer-Rokitansky-Kuster-Hauser syndrome.
\end{abstract}

DOI: https://doi.org/10.1159/000152037

Posted at the Zurich Open Repository and Archive, University of Zurich ZORA URL: https://doi.org/10.5167/uzh-5508

Journal Article

Published Version

Originally published at:

Biason-Lauber, A; Konrad, D (2008). WNT4 and sex development. Sexual Development, 2(4-5):210-218. DOI: https://doi.org/10.1159/000152037 


\title{
Review Article
}

\section{WNT4 and Sex Development}

\author{
A. Biason-Lauber D. Konrad \\ University Children's Hospital, Zurich, Switzerland
}

\section{Key Words}

Meyer-Rokitansky-Kuster-Hauser • Müllerian ducts • Ovarian development - Syndrome hyperandrogenism. WNT

\begin{abstract}
Although factors involved in male sexual differentiation have been well studied, the pathways regulating female sexual differentiation remain incompletely defined. To date, no genes have been identified to play a similar role in ovarian development as was shown for the SRY or SOX9 genes in testicular development. In mice, Wnt4 regulates the development of the female reproductive tract, antagonizes the production of testosterone, and is important for oocyte development. The recent demonstration of heterozygous WNT4 defects in patients with Müllerian agenesis and signs of ovarian hyperandrogenism added WNT4 to the growing list of genes such as SRY, SOX9, WT1, DAX1, and SF-1 contributing to human sexual development. In particular, WNT4 was the first human gene to be identified to direct development of the bipotential gonad towards ovaries. From a more clinical point of view, it seems that the absence of a uterus (and not other Müllerian abnormalities) and the androgen excess are the pathognomonic signs of WNT4 defects, suggesting that WNT4 deficiency might be a clinical entity distinct from the typical Mayer-Rokitansky-Kuster-Hauser syndrome.
\end{abstract}

Copyright $\odot 2008$ S. Karger AG, Basel

\section{KARGER}

Fax +4161306 1234

E-Mail karger@karger.ch

www.karger.com (c) 2008 S. Karger AG, Basel

1661-5425/08/0025-0210\$24.50/0

Accessible online at:

www.karger.com/sxd

\section{Physiology of Sex Development}

Among all definitions of sexual differentiation, we like the one from Wikipedia the best: 'Sexual differentiation is the process of development of the differences between males and females from an undifferentiated zygote (fertilized egg). As male and female individuals develop from zygotes into fetuses, into infants, children, adolescents, and eventually into adults, sex and gender differences at many levels develop: genes, chromosomes, gonads, hormones, anatomy, psyche, and social behaviors'. In sex development we can distinguish two different processes: sex determination that is the developmental decision that directs the undifferentiated embryo into a sexually dimorphic individual and sex differentiation that takes place once the sex determination decision has been made through factors produced by the gonads that determine the development of the phenotypic sex. At the beginning of gestation (1st and 2nd week) embryos of the two sexes differ only in their karyotypes. Starting at week 3, specific genes lead to the differentiation of the gonads which in turn produce hormones inducing anatomical and psychological differences and lead to behavioral differences that are ultimately influenced by the social environment. The main steps of intrauterine sex differentiation are depicted in figure 1. At gestational weeks 6-7 the paramesonephric duct (Müllerian duct) develops next to the mesonephric duct. If testes develop and secrete testosterone, 


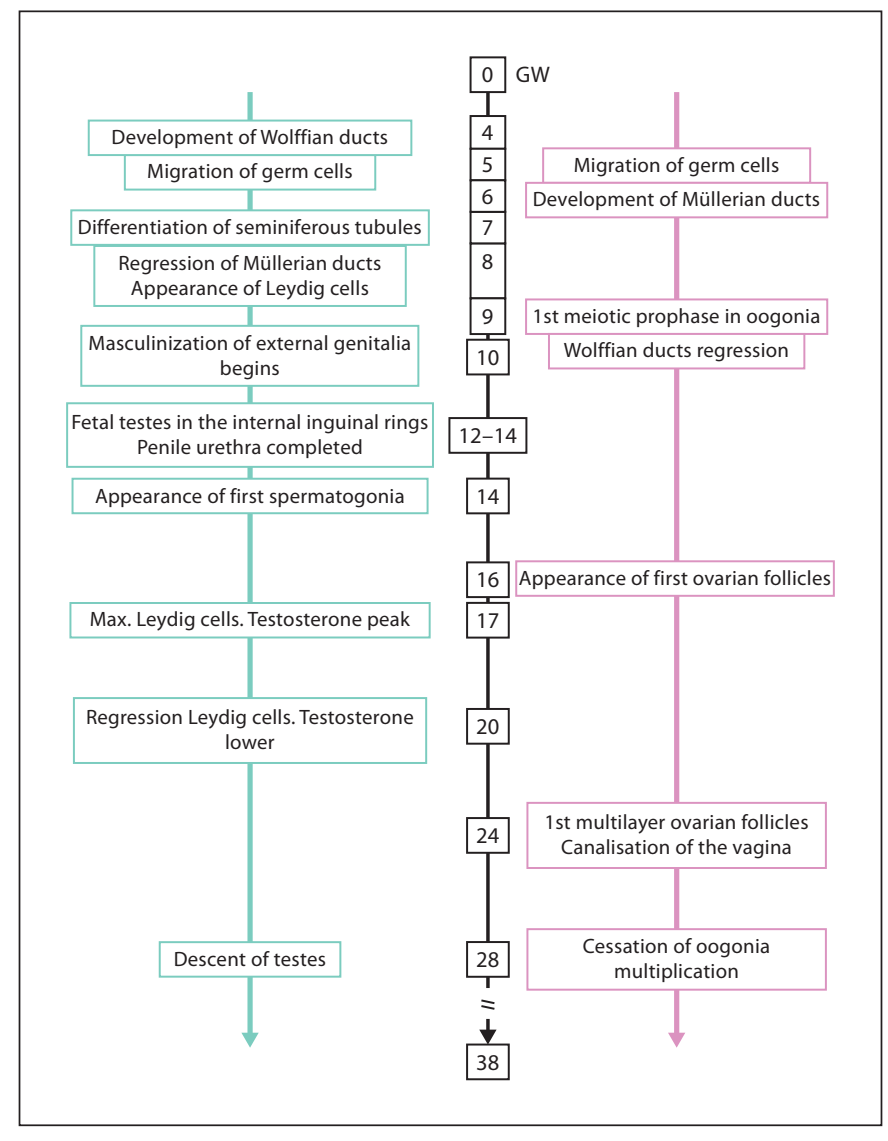

Fig. 1. Embryonic development. GW: Gestational week. Data derived from Bertrand et al. [1993].

the mesonephric (Wolffian) duct increases in size and differentiates into epididymis, vas deferens, and prostate. A glycoprotein secreted from the Sertoli cells, known as anti-Müllerian hormone (AMH) or Müllerian inhibiting substance (MIS), results in Müllerian duct regression. If testes do not develop, the mesonephric duct does not grow and eventually degenerates, whereas the paramesonephric duct proliferates and the fallopian tube, uterus, and upper third of the vagina develop (fig. 2).

In mammals, including humans, the differentiation of the gonads is the turning point of this whole process. The classical textbook theory says that in the presence of the sex determining region on the Y chromosome (SRY), the default ovarian pathway of sex determination will be inhibited and therefore testes will be formed. In the XX individual, due to the absence of $S R Y$, no inhibition of the default program will take place and ovaries will develop.

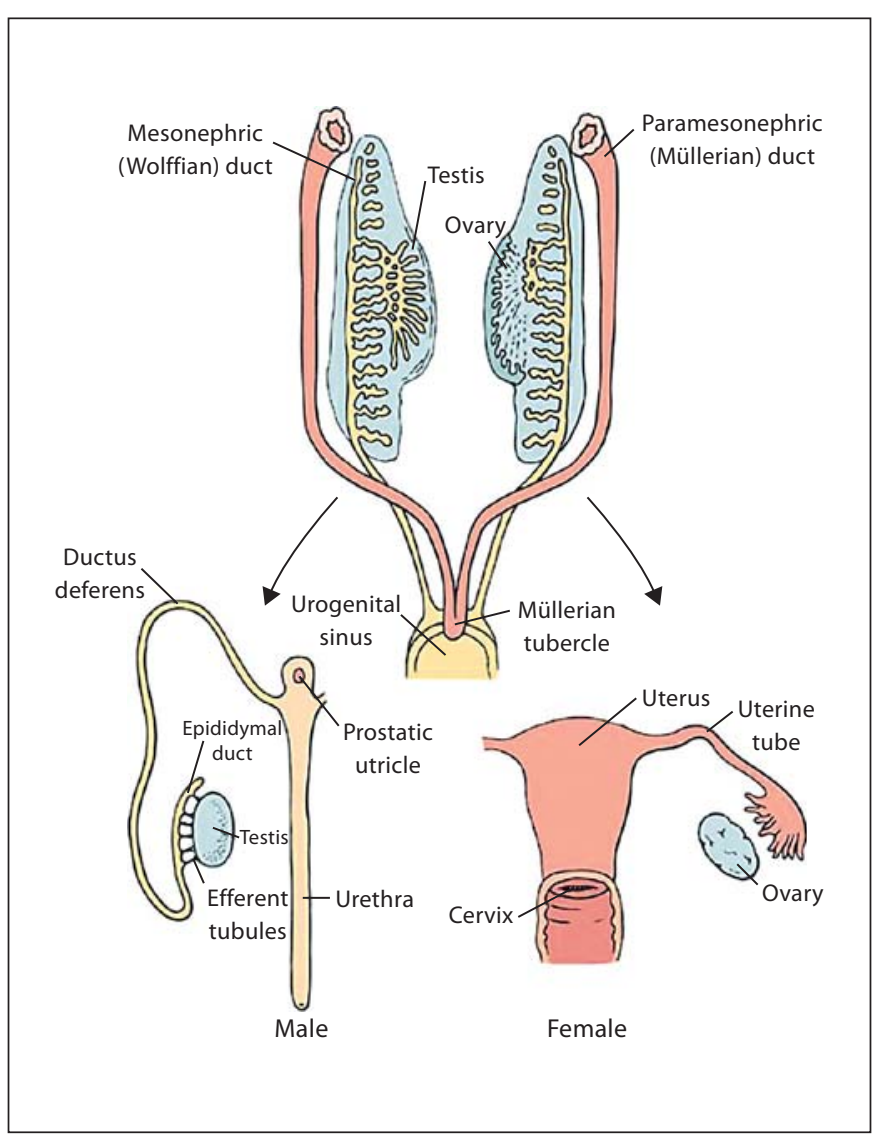

Fig. 2. The undifferentiated sexual system at 6-7 weeks of gestation. Precursor structures (top) and their mature counterparts (bottom) have the same color. From Stenchever and Goldfarb [1998].

Ovarian determining factors might help the process of differentiation. However, these factors are yet to be determined. The second model, called the Z-factor theory, was proposed to explain the cases where XX individuals develop testes in the absence of SRY. According to this theory, the XX gonad expresses a factor that has both antitestis and pro-ovary function. SRY in XY individuals acts as an inhibitor of the Z-factor to lift the block on the male pathway. In this case, the bipotential gonad will differentiate into a testis [McElreavey et al., 1993].

Although factors involved in male sexual differentiation have been well studied (fig. 3), the pathways regulating female sexual differentiation remain incompletely defined. To date, no genes have been identified to play a similar role in ovarian development as it was shown for the $S R Y$ or $S O X 9$ gene in testicular development. In mice, Wnt 4 , one of a few factors with a demonstrated function 


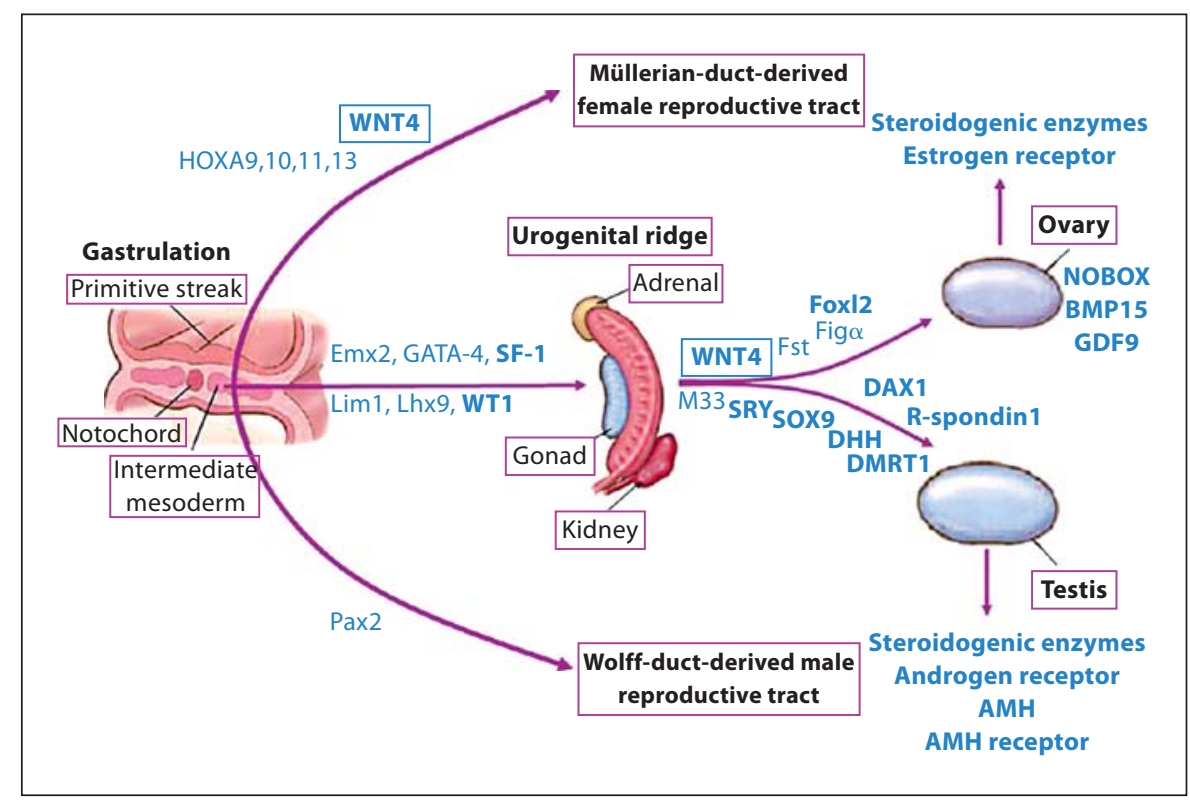

Fig. 3. Sexual differentiation cascade. Mutations in various genes (bold) can lead to a variety of syndromes of dysgenesis involving the Müllerian or Wolffian ducts, gonads, kidneys, and adrenal glands as a result of a deficiency or excess of the proteins shown. BMP15: bone morphogenic factor 15; DAX1: dosage dependent adrenal hypoplasia congenita on the $\mathrm{X}$ chromosome gene $1 ; \mathrm{DHH}$ : desert hedgehog; DMRT1: doublesex- and Mab3-related transcription factor 1; Emx2: empty spiracles homeobox gene 2; Fig $\alpha$ : factor in germline alpha; Foxl2: forkhead transcription factor; Fst: follicostatin; GDF9: growth differentiation factor 9; GATA-4: gene encoding a protein that binds to a GATA DNA sequence; HOXA: homeobox protein; $L h x 9$ : lim homeobox family member; Lim1: homeobox gene important for limb development; M33: polycomb like protein, essential for male sexual differentiation in mice; NOBOX: newborn ovary homeobox transcription factor; $P A X 2$ : paired box homeotic gene; SF-1: gene for steroidogenic factor 1; SRY: sex-determining region of the Y chromosome; SOX9: SRY homeobox 9; Wnt4: wingless-type MMMTV integration site family member 4; WT1: Wilms' tumor-suppressor gene 1. Modified from McLaughlin and Donahoe [2004].

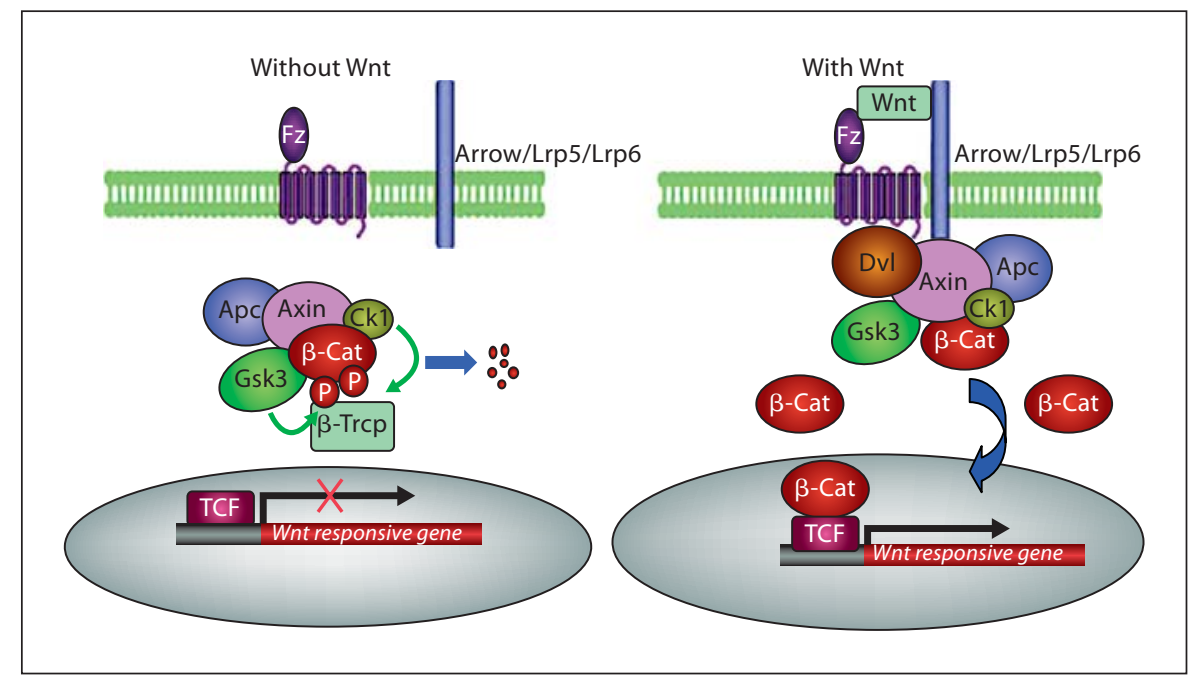

Fig. 4. Wnt signaling cascade. When a WNT signal arrives at the cell surface, it stimulates the 'Frizzled' receptor and/or LDL-receptor related proteins 5 and 6 and arrow. This inhibits the degradation complex, blocking the elimination of $\beta$-catenin. $\beta$-Catenin migrates to the nucleus and stimulates expression of genes in con- cert with TCF. That in turn regulates embryonic induction, cell polarity, and cell fate. Apc: adenomatous polyposis of the colon; $\beta$-Cat: $\beta$-catenin; Ck1: casein kinase 1; Dvl: disheveled; Fz: frizzled; Gsk3: glycogen synthase kinase 3; Lrp: LDL-receptor related protein; TCF: T-cell transcription factor. From He et al. [2004]. 
in the ovarian-determination pathway, has been found to be involved in sexual differentiation by suppressing male sexual differentiation, promoting Müllerian ducts differentiation, and maintaining oocyte health (see below).

\section{WNT4 and Sex Development}

WNT4 (wingless-type MMTV integration site family, member 4) is a member of the WNT family of secreted molecules that function in a paracrine manner to affect a number of developmental changes. Wnt proteins bind to members of the frizzled $(\mathrm{Fz})$ family of cell surface receptors and possibly to the single-pass transmembrane protein LDL-receptor-related proteins 5 and 6 (Lrp5 and Lrp6) [He et al., 2004]. The binding of Wnt to Fz leads to activation of the phosphoprotein dishevelled (Dsh or Dvl). The activation and membrane recruitment of Dsh probably recruits Axin and the destruction complex to the plasma membrane, where Axin directly binds to the cytoplasmic tail of Lrp5/6. Axin is then degraded, which decreases $\beta$-catenin degradation. The activation of Dsh also leads to the inhibition of Gsk3, which further reduces the phosphorylation and degradation of $\beta$-catenin with consequent $\beta$-catenin-dependent activation of $\mathrm{T}$ cell factor/lymphocyte enhancer factor transcription factors, and induction of Wnt-responsive genes (fig. 4) [Nusse, 2003]. Wnt proteins can also signal via a $\beta$-catenin independent non-canonical pathway involving protein kinase $\mathrm{C}(\mathrm{Pkc})$ and c-Jun NH2-terminal kinase (Jnk) [Pandur et al., 2002]. (Readers interested in learning more about WNT proteins should visit the informative site http://www.stanford.edu/ rnusse/wntwindow.html).

Wnt4 is produced in ovarian somatic cells (pre-granulosa cells). It up-regulates Dax1 [Jordan et al., 2001], a gene known to antagonize the nuclear-receptor steroidogenic factor 1 and thereby inhibits steroidogenic enzymes. Vainio and collaborators [Vainio et al., 1999] observed in Wnt4 deficient mice that gonadal development and steroidogenic function were affected exclusively in female Wnt4 knockout mice, whereas both male and female mice had similar defects in kidney development and adrenal function. Wnt4 knockout female mice were masculinized, as demonstrated by the absence of Müllerian ducts and the presence of Wolffian ducts and expressed the steroidogenic enzymes $3 \beta$-hydroxysteroid dehydrogenase and $17 \alpha$-hydroxylase, which are required for the production of testosterone and are normally suppressed in the developing female ovary. The ovaries of these mice also had less oocytes suggesting a role of Wnt4 in the life of female germ cells. This function is crucial for the organization of ovarian structure, since female germ cells have a central role in this process and in maintenance of the ovary, as demonstrated by the fact that when oocytes are either absent [Merchant, 1975] or lost after follicle formation [McLaren, 1984], ovarian follicles never form or degenerate subsequently. In contrast, testis development proceeds in the absence of germ cells. WNT4 and follicostatin [Yao et al., 2004] appear to maintain oocyte viability once germ cells have reached their final destination in the gonad. Downstream of WNT4, two oocyte-specific transcription factors, among others, also play alpha critical role in oocyte survival: factor in the germline alpha (FIG $\alpha$, FIGLA) [Liang et al., 1997] and newborn ovary homeobox-encoding gene (NOBOX) [Rajkovic et al., 2004]. Absence of these genes results in oocyte death and prevents the subsequent formation of primordial follicles because of a failure of the ovigerous cords to become follicles [Soyal et al., 2000]. After FIG $\alpha$ has been activated in oocytes, another transcription factor, forkhead transcription factor FOXL2, is turned on to regulate the differentiation of somatic granulosa cells for folliculogenesis. Fbxw15/Fbxo12J, an F-box containing gene specifically expressed in mouse ovary, was recently shown to possibly contribute to ovarian physiology by preventing oocytes from exiting meiotic prophase or by regulating signaling events required for oocyte-granulosa cell communication [De La Chesnaye et al., 2008]. Bone morphogenic protein 15 (BMP15) and growth differentiation factor 9 (GDF9) are crucial for ovarian follicle physiology, probably by controlling its metabolism [Su et al., 2008]. In women, BMP15 and NOBOX mutations have been associated with premature ovarian failure [Di Pasquale et al., 2004, 2006; Dixit et al., 2006; Qin et al., 2007], whereas GDF9 aberrant expression and genomic variants have been linked to premature ovarian failure and twin pregnancy, respectively [Chand et al., 2006; Palmer et al., 2006; Kovanci et al., 2007]. FOXL2 mutations have been associated to blepharophimosis/ptosis/epicanthus inversus syndrome (BPES) and premature ovarian failure [Harris et al., 2002]. Maintenance of follicle 'identity' is guaranteed by estrogen formation and action, as demonstrated by the transdifferentiation of normally formed ovarian tissue into testicular structures in mice lacking the enzyme aromatase (converting androgens to estrogens) [Britt and Findlay, 2003] and/or estrogen receptor [Couse et al., 1999; Dupont et al., 2000]. None of these factors, however, except maybe WNT4, have a similar role in ovarian development as SRY or SOX9 in testis differentiation. Figure 5 depicts this cascade. 
Fig. 5. Simplified diagram of the ovarian germ cell/follicle developmental cascade. For abbreviations of factors see legend of figure 3. ER: estrogen receptor.

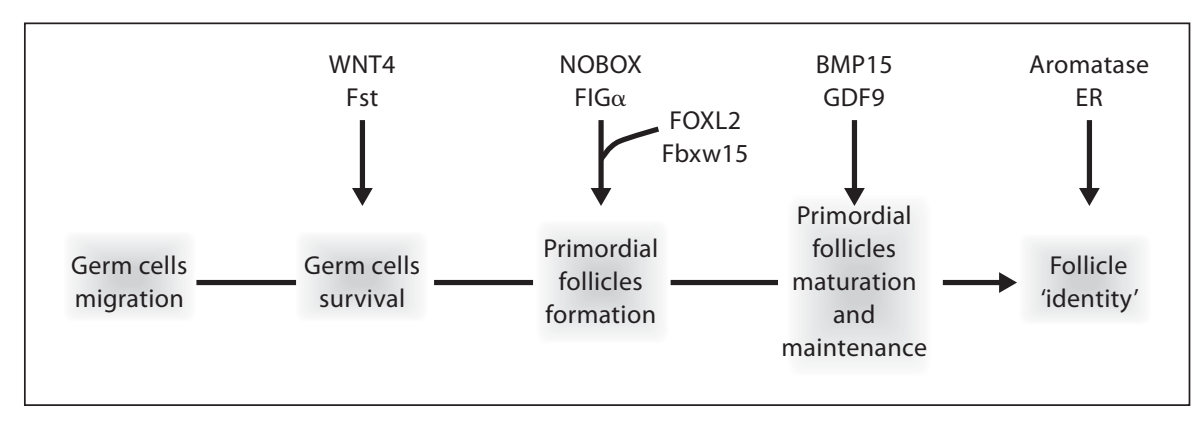

\section{WNT4 Deficiency: Implications for Human Sex Development}

In humans, more copies of WNT4, due to duplication of chromosome $1 \mathrm{p} 31 \rightarrow \mathrm{p} 35$, were found in a patient with ambiguous genitalia, severe hypospadias, fibrous gonads and remnants of both Müllerian and Wolffian ducts [Jordan et al., 2001], i.e., male-to-female sex reversal. On the other end of the spectrum, when both copies of the gene are inactive, as in the case of homozygote mutations, a severe clinical entity called the SERKAL syndrome results [Mandel et al., 2008]. The syndrome was described in three $46, \mathrm{XX}$ fetuses and is characterized by female-tomale sex reversal with ambiguous genitalia, gonadal morphology ranging from ovotestis to normal testis, renal agenesis, adrenal hypoplasia, and pulmonar and cardiac abnormalities.

In the middle of such spectrum one might expect to find patients with intermediate defects of sex development. Searches for clinically relevant WNT4 mutations sometimes in large cohorts of such patients were unsuccessful [Domenice et al., 2004]. We described a woman with absent Müllerian structures (uterine and fallopian tubes) who had unilateral renal agenesis (fig. 6) and clinical signs of androgen excess. Her phenotype resembles that of patients with the Mayer-Rokitansky-Kuster-Hauser (MRKH) syndrome and is also strikingly similar to that of Wnt4 knockout female mice. This constellation of findings prompted us to search for mutations in the WNT4 gene in this patient.

Direct sequencing of PCR-amplified exonic fragments revealed a heterozygous mutation leading to a heterozygous E226G/WT missense exchange in the WNT4 protein. In search for causes of the defective signaling, we found that the E226G mutant protein appears to be trapped inside the cell [Biason-Lauber et al., 2004], likely because of defective post-translational lipid modification necessary for WNT proper function [Nusse, 2003]. Since

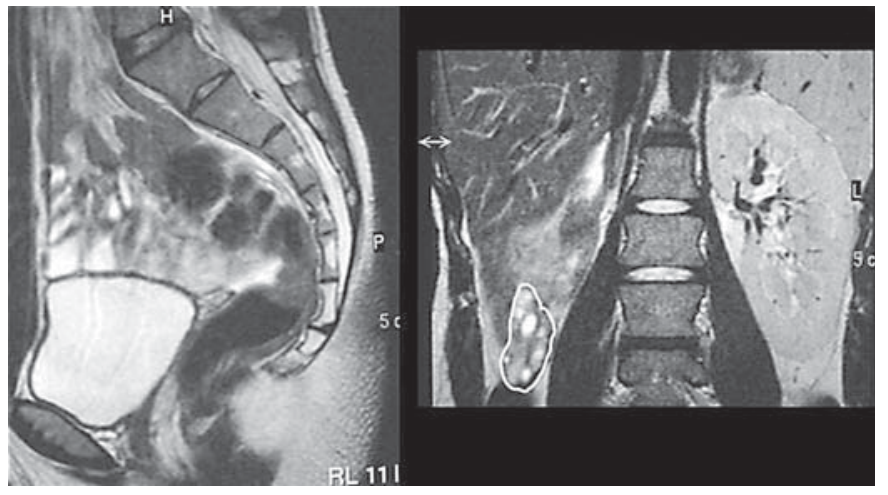

Fig. 6. Magnetic resonance imaging of the abdominal cavity of the first WNT4 deficient patient, showing lack of uterus and tubes (left panel), the renal agenesis, and the ectopic ovary (right panel).

any generalizations regarding the role of WNT4 in humans, however, must await the description and characterization of mutations in additional patients, we searched for additional subjects with WNT4 mutations. The recent identification of a second [Biason-Lauber et al., 2007] and a third patient [Philibert et al., 2008] with a similar phenotype and mutations in WNT4 (R83C and L12P, respectively) confirmed its role in ovarian and female reproductive tract development in women. The disease-causing WNT4 mutations are depicted in figure 7 . These additional patients also helped to refine the phenotype of WNT4 deficiency in humans. In fact, it appears that the absence of a uterus (and not other Müllerian abnormalities) and the androgen excess are the pathognomonic signs of WNT4 defects, suggesting that this might be a clinical entity distinct from the classical Mayer-Rokitansky-Kuster-Hauser syndrome. The functional studies performed in these cases suggested that the consequences of the present WNT4 mutations range from lack of lipid modification (and probable misfolding) [Biason-Lau- 
Fig. 7. Known mutations in the WNT4 gene causing disease. The heterozygote mutations were found in women with no uterus and signs of virilization. The homozygote mutation (boxed) is linked to a more severe entity, called SERKAL syndrome.

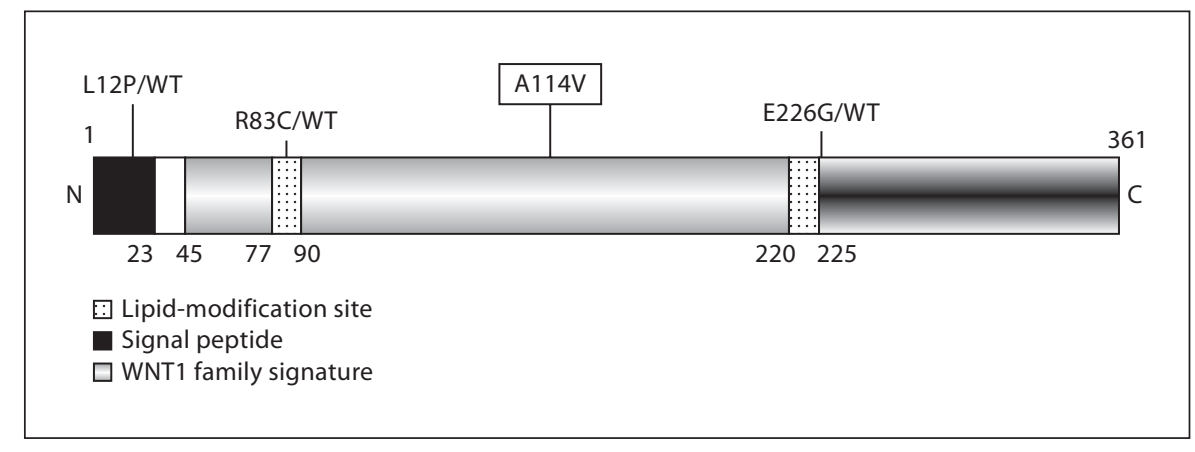

ber et al., 2004] to misfolding and formation of intractable aggregates [Biason-Lauber et al., 2007] to defects in receptor binding [Philibert et al., 2008]. The fact that these patients are heterozygous and the results of the expression studies suggest that one normal copy of WNT4 is not only inadequate to maintain protein function, but is also negatively influenced by the mutant protein (dominant negative effect). Although this is not a classical gene-dosage phenomenon, since the gene copies are the same (except in the duplication case), it is certainly a dosage-sensitive sex determining process, as Jordan and coworkers already predicted [Jordan et al., 2001]. In fact, while too much WNT4 activity (duplication) induces feminization of the male, too little WNT4 activity (homozygous loss-of-function mutation) induces exactly the opposite, i.e., masculinization of the female. Since WNT4 inhibits the male development in the female and males do not need WNT4 for their sex development [Vainio et al., 1999], situations between these two extremes are characterized by different degrees of masculinization of the female. Although the presence of negative dominance renders the case arithmetically more complex, the relationship between activity levels and phenotype of WNT4 abnormalities is rather striking (fig. 8) and corroborates the idea that sex differentiation is a matter of dosage. A general view of the role of WNT4 in sexual development is depicted in figure 9.

\section{Conclusions}

The idea that the female sexual development happens by default was born in the middle of the last century after Jost [1970] carried out his innovative experiments to study the bases of differentiation of the reproductive tract and was based on the fact that the female reproductive tract develops even in the absence of any gonad. The term default (passive), attributed to the ovarian developmental pathway, therefore established itself even if it was not originally so intended.

However, recent findings have demonstrated that ovarian development in its early stages is an active process. The role of WNT4 (and follicostatin) in this process is to suppress the migration of mesonephric endothelial and steroidogenic cells preventing the formation of malespecific coelomic blood vessels and the production of steroids [Jeays-Ward et al., 2003; Yao et al., 2004]. Furthermore, Wnt 4 appears to protect the germ cells in mice [Vainio et al., 1999] and probably in humans [Philibert et al., 2008].

Although Wnt4/follicostatin has an anti-testis (anticoelomic vessel) and a pro-ovarian action (germ cell protection), they do not fit to the Z-factor profile because they influence a marginal aspect of testicular differentiation. Nevertheless, these anti-testis/pro-ovary properties and the fact that WNT4/follicostatin are made by somatic cells (similar to what happens for male-specific factors in the testis) render the WNT4/follicostatin duo an intriguing candidate for the role of the ovarian determining factor.

Also, it is appealing to us and others in the field [Yao, 2005] to speculate that the development of testicular structures in XX individuals who do not have SRY or any activation of its down-stream targets, points to the possibility that maybe the development of testes is the default pathway.

From a more clinical point of view, we agree with Clement-Ziza et al. [2005] that it should not be looked for WNT4 mutations in MRKH syndrome. However, MRKH-like syndromes associated with hyperandrogenism should be investigated for mutations in this gene and may classify for a distinct clinical entity. 
Fig. 8. Hypothetical relationship between WNT4 dosage and manifestation of disease. Normal function (and dosage) is set as 1.0. Heterozygote mutations have a dominant negative effect (red line) on the wild type protein and lower the activity by $20 \%$ instead of the expected $50 \%$. ' [Jordan et al., 2001]; b[Biason-Lauber et al., 2004, 2007; Philibert et al., 2008]; ' [Mandel et al., 2008].

Fig. 9. WNT4 and human sex development. The development of the genital ridge and bipotential gonad is under similar control in the two sexes. An ovary develops in the absence of $S R Y$ and $S O X 9$ action, possibly because of the anti-testis effects of DAX1 and WNT4. Steroidogenesis is delayed in the ovary by the action of WNT4, which is also needed for the development of the Müllerian ducts and germ cell survival. A testis develops as a result of $S R Y$ and SOX9 action, complemented by DAX1. The regression of the Müllerian ducts is mediated by anti-Müllerian hormone $(\mathrm{AMH})$ and its receptor (AMH-Rec), whereas the androgenic stabilization of the Wolffian ducts and the differentiation of the external genitalia are mediated by the androgen receptor (AR). The descent of the testes is partially mediated by the insulin-like 3 ligand (Insl3) and its receptor (Lgr8). Modified from Hughes [2004].
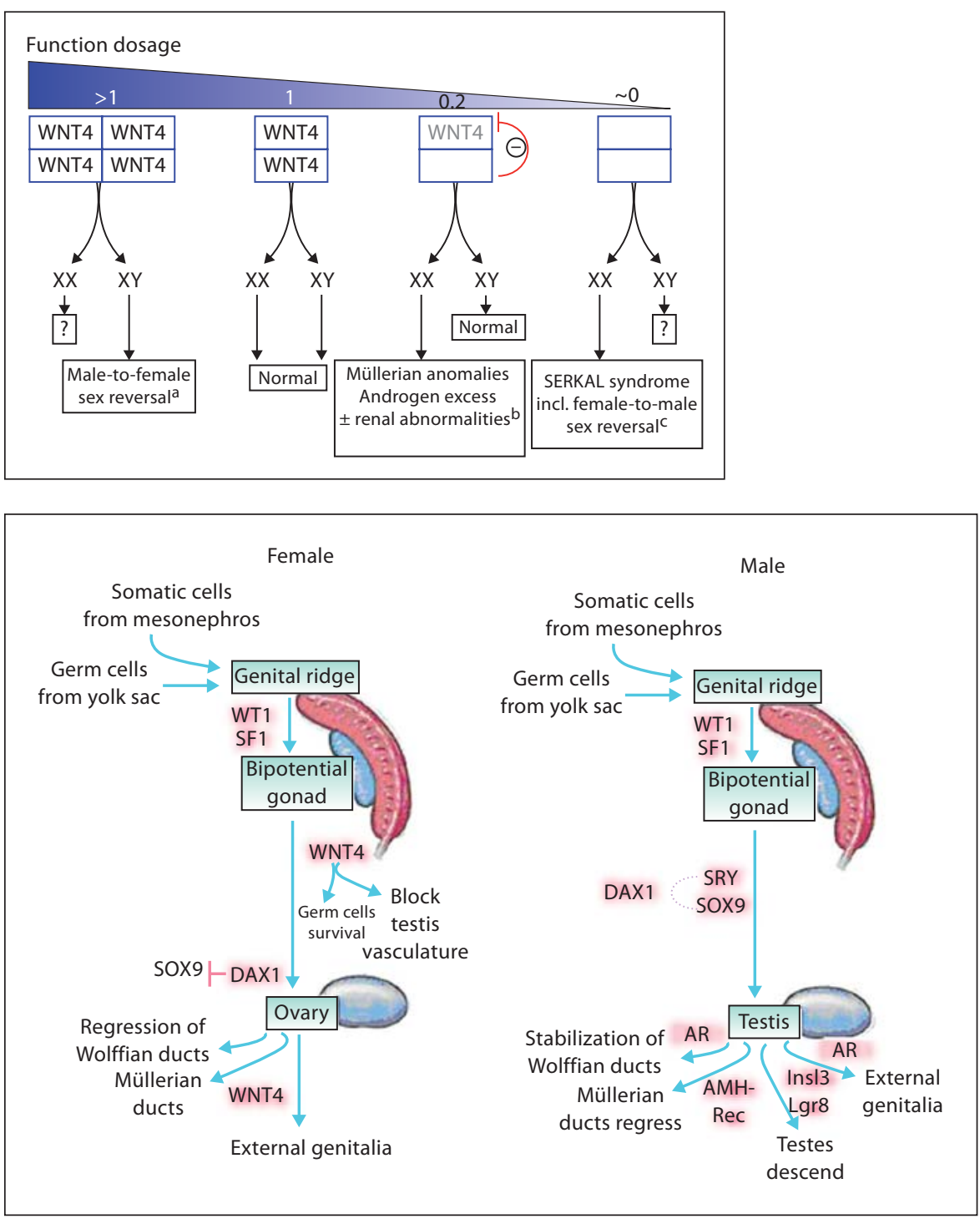

\section{Future Perspectives}

Given the role of WNT4 in the maintenance of the female phenotype of the ovaries, polymorphisms or milder defects of this gene and dysregulation of protein function are obvious candidates for functional hyperandrogenic states such as polycystic ovary (PCO) disease. The altered expression of components of WNT signaling in PCO theca cells (demonstrated by gene expression profiling) [Wood et al., 2004] suggests an inhibition of the pathway and adds further weight to this idea. Thus, there is a need for a better characterization of the WNT4 signaling pathway in ovarian tissues in order to estimate its potential contribution to functional hyperandrogenic states. Mod- ulation of WNT4 signaling may turn out to be beneficial in the treatment of polycystic ovary disease or other forms of hyperandrogenism in future.

Animal experiments demonstrated that a major role of Wnt4 in adrenal development is to prevent the gonadal programming of the adrenal cortex. An additional function might also include the maintenance of a functional zona glomerulosa, because aldosterone production in $W n t 4^{-/-}$mice is significantly reduced [Heikkila et al., 2002]. Wnt 4 is thought to act by inhibiting the synergy between $\beta$-catenin and Sf- 1 on its targets in vitro [Jordan et al., 2003] suggesting a role in noncanonical Wnt signaling in adrenals. Although in adult human adrenal glands WNT4 is the only member of the WNT family to be ex- 
pressed [Suwa et al., 2003], there is no evidence of impaired aldosterone secretion in WNT4 deficient heterozygous patients (normal aldosterone levels, normal PRA, normal electrolytes). The homozygous deficient fetuses had smaller adrenals (as in mice), but no biochemical studies are available. This might be due to species-specific differences or to the fact that the identified mutations do affect the canonical pathway, but not the non- canonical. The role of canonical and non-canonical WNT4 signaling in human adrenals, with focus on aldosterone production, needs yet to be explored and could have implications for the regulation of salt-water balance and hypertension. One could even speculate that certain polymorphisms of WNT4 may predispose to or protect against the development of essential hypertension.

\section{References}

Bertrand J, Rappaport R, Sizonenko PC: Pediatric Endocrinology, pp 88-99 (Williams \& Wilkins, Baltimore 1993).

Biason-Lauber A, Konrad D, Navratil F, Schoenle EJ: A WNT4 mutation associated with Mullerian-duct regression and virilization in a 46,XX woman. N Engl J Med 351:792798 (2004)

Biason-Lauber A, De Filippo G, Konrad D, Scarano G, Nazzaro A, Schoenle EJ: WNT4 deficiency - a clinical phenotype distinct from the classic Mayer-Rokitansky-Kuster-Hauser syndrome: a case report. Hum Reprod 22: 224-229 (2007).

Britt KL, Findlay JK: Regulation of the phenotype of ovarian somatic cells by estrogen. Mol Cell Endocrinol 202:11-17 (2003).

Chand AL, Ponnampalam AP, Harris SE, Winship IM, Shelling AN: Mutational analysis of $B M P 15$ and GDF9 as candidate genes for premature ovarian failure. Fertil Steril 86:10091012 (2006).

Clement-Ziza M, Khen N, Gonzales J, CretolleVastel C, Picard JY, et al: Exclusion of WNT4 as a major gene in Rokitansky-Kuster-Hauser anomaly. Am J Med Genet A 137:98-99 (2005).

Couse JF, Hewitt SC, Bunch DO, Sar M, Walker VR, et al: Postnatal sex reversal of the ovaries in mice lacking estrogen receptors alpha and beta. Science 286:2328-2331 (1999).

De La Chesnaye E, Kerr B, Paredes A, MerchantLarios H, Mendez JP, Ojeda SR: Fbxw15/ Fbxo12J is an F-box protein-encoding gene selectively expressed in oocytes of the mouse ovary. Biol Reprod 78:714-725 (2008).

Di Pasquale E, Beck-Peccoz P, Persani L: Hypergonadotropic ovarian failure associated with an inherited mutation of human bone morphogenetic protein-15 (BMP15) gene. Am J Hum Genet 75:106-111 (2004).

Di Pasquale E, Rossetti R, Marozzi A, Bodega B, Borgato $S$, et al: Identification of new variants of human BMP15 gene in a large cohort of women with premature ovarian failure. J Clin Endocrinol Metab 91:1976-1979 (2006).
Dixit H, Rao LK, Padmalatha VV, Kanakavalli M, Deenadayal M, Gupta N, et al: Missense mutations in the BMP15 gene are associated with ovarian failure. Hum Genet 119:408415 (2006).

Domenice S, Corrêa RV, Costa EM, Nishi MY, Vilain E, et al: Mutations in the SRY, DAX1, SF1 and WNT4 genes in Brazilian sex-reversed patients. Braz J Med Biol Res 37:145150 (2004).

Dupont S, Krust A, Gansmuller A, Dierich A Chambon P, Mark M: Effect of single and compound knockouts of estrogen receptors alpha (ERalpha) and beta (ERbeta) on mouse reproductive phenotypes. Development 127: 4277-4291 (2000).

Harris SE, Chand AL, Winship IM, Gersak K, Aittomaki K, Shelling AN: Identification of novel mutations in FOXL2 associated with premature ovarian failure. Mol Hum Reprod 8:729-733 (2002).

He X, Semenov M, Tamai K, Zeng X: LDL receptor-related proteins 5 and 6 in Wnt/betacatenin signaling: arrows point the way. Development 131:1663-1677 (2004).

Heikkila M, Peltoketo H, Leppaluoto J, Ilves M, Vuolteenaho O, Vainio S: Wnt-4 deficiency alters mouse adrenal cortex function, reducing aldosterone production. Endocrinology 143:4358-4365 (2002).

Hughes IA: Female development - all by default? N Engl J Med 351:748-750 (2004).

Jeays-Ward K, Hoyle C, Brennan J, Dandonneau M, Alldus G, et al: Endothelial and steroidogenic cell migration are regulated by WNT4 in the developing mammalian gonad. Development 130:3663-3670 (2003).

Jordan BK, Mohammed M, Ching ST, Delot E, Chen XN, et al: Up-regulation of WNT- 4 signaling and dosage-sensitive sex reversal in humans. Am J Hum Genet 68:1102-1109 (2001).

Jordan BK, Shen JH, Olaso R, Ingraham HA, Vilain E: Wnt4 overexpression disrupts normal testicular vasculature and inhibits testosterone synthesis by repressing steroidogenic factor 1/beta-catenin synergy. Proc Natl Acad Sci USA 100:10866-10871 (2003).
Jost A: Hormonal factors in the sex differentiation of the mammalian foetus. Phil Trans R Soc Lond B Biol Sci 259:119-130 (1970).

Kovanci E, Rohozinski J, Simpson JL, Heard MJ, Bishop CE, Carson SA: Growth differentiating faxtor-9 mutations may be associated with premature ovarian failure. Fertil Steril 87:143-146 (2007)

Liang L, Soyal SM, Dean J: FIGalpha, a germ cell specific transcription factor involved in the coordinate expression of the zona pellucida genes. Development 124:4939-4947 (1997).

MacLaughlin DT, Donahoe PK: Sex determination and differentiation. N Engl J Med 350: 367-378 (2004).

Mandel H, Shemer R, Borochowitz ZU, Okopnik M, Knopf C, et al: SERKAL syndrome: an autosomal-recessive disorder caused by a lossof-function mutation in WNT4. Am J Hum Genet 82:39-47 (2008).

McElreavey K, Vilain E, Abbas N, Herskowitz I, Fellous M: A regulatory cascade hypothesis for mammalian sex determination: SRY represses a negative regulator of male development. Proc Natl Acad Sci USA 90:3368-3372 (1993).

McLaren A: Meiosis and differentiation of mouse germ cells. Symp Soc Exp Biol 38:7-23 (1984).

Merchant H: Rat gonadal and ovarian organogenesis with and without germ cells. An ultrastructural study. Dev Biol 44:1-21 (1975).

Nusse R: Wnts and Hedgehogs: lipid-modified proteins and similarities in signaling mechanisms at the cell surface. Development 130: 5297-5305 (2003).

Palmer JS, Zhao ZZ, Hoekstra C, Hayward NK, Webb PM, et al: Novel variants in growth differentiation factor 9 in mothers of dizygotic twins. J Clin Endocrinol Metab 91: 4713-4716 (2006).

Pandur P, Lasche M, Eisenberg LM, Kuhl M: Wnt-11 activation of a non-canonical Wnt signalling pathway is required for cardiogenesis. Nature 418:636-641 (2002). 
Philibert P, Biason-Lauber A, Rouzier R, Pienkowski C, Paris F, et al: Identification and functional analysis of a new WNT4 gene mutation among 28 adolescent girls with primary amenorrhea and Mullerian duct abnormalities: a French collaborative study. J Clin Endocrinol Metab 93:895-900 (2008).

Qin Y, Choi Y, Zhao H, Simpson JL, Chen ZJ, Rajkovic A: NOBOX homeobox mutation causes premature ovarian failure. Am J Hum Genet 81:576-581 (2007).

Rajkovic A, Pangas SA, Ballow D, Suzumori N, Matzuk MM: NOBOX deficiency disrupts early folliculogenesis and oocyte-specific gene expression. Science 305:1157-1159 (2004).

Soyal SM, Amleh A, Dean J: FIGalpha, a germ cell-specific transcription factor required for ovarian follicle formation. Development 127:4645-4654 (2000).
Stenchever MA, Goldfarb AF: Atlas of Clinical Gynecology, Volume 1: Pediatric and Adolescent Gynecology (Appleton \& Lange, U.S. 1998).

Su YQ, Sugiura K, Wigglesworth K, O’Brien MJ, Affourtit JP, et al: Oocyte regulation of metabolic cooperativity between mouse cumulus cells and oocytes: BMP15 and GDF9 control cholesterol biosynthesis in cumulus cells. Development 135:111-121 (2008).

Suwa T, Chen M, Hawks CL, Hornsby PJ: Zonal expression of dickkopf-3 and components of the Wnt signalling pathways in the human adrenal cortex. J Endocrinol 178:149-158 (2003).
Vainio S, Heikkila M, Kispert A, Chin N, McMahon AP: Female development in mammals is regulated by Wnt- 4 signalling. Nature 397: 405-409 (1999).

Wood JR, Ho CK, Nelson-Degrave VL, McAllister JM, Strauss JF 3rd: The molecular signature of polycystic ovary syndrome (PCOS) theca cells defined by gene expression profiling. J Reprod Immunol 63:51-60 (2004).

Yao HH: The pathway to femaleness: current knowledge on embryonic development of the ovary. Mol Cell Endocrinol 230:87-93 (2005).

Yao HH, Matzuk MM, Jorgez CJ, Menke DB, Page DC, et al: Follistatin operates downstream of Wnt4 in mammalian ovary organogenesis. Dev Dyn 230:210-215 (2004). 